\title{
Microbiological Quality of Drinking Water from Water Dispenser Machines
}

\author{
Merfat Ebrahim Al Moosa, Munawwar Ali Khan, Usama Alalami, and Arif Hussain
}

\begin{abstract}
The aim of this study was to investigate the microbial quality of drinking water distributed through water dispenser machines located in schools and universities in Ajman, UAE. In total, 49 drinking water samples were collected from water dispenser machines in the schools and university's premises in the emirate of Ajman. Total coliform and E.coli were detected using Colilert test. $P$. aeruginosa colonies were counted on Pseudomonas agar using the membrane filtration method. Overall, 25 out of total 49 samples were found to contain either P. aeruginosa, or total coliform or both. Six samples were found positive for total coliform group members, whereas nineteen of the samples were positive for $P$. aeruginosa. Ten water samples were found positive for both total coliform and P.aeruginosa. P.aeruginosa colonies count ranged between 4 to 51 colonies per $250 \mathrm{ml}$ of water sample. In conclusion, overall microbiological quality of 25 drinking water samples distributed through the water dispenser machine was found unsatisfactory, and this could be attributed to the poor maintenance and improper hygienic conditions of water dispenser machines. In order to safeguard public health, more efforts such as community awareness program, strict regulations such as regular inspections by the local municipalities are needed.
\end{abstract}

Index Terms-Microbiological quality, drinking water, water dispenser.

\section{INTRODUCTION}

Water is a very important resource needed to sustain life, and safe drinking water is a fundamental requirement for human life [1]. The availability of safe drinking water represents a global challenge, and authorities sustain substantial efforts in two priority areas: water quantity and water quality assurance [2]. The deterioration of water quality primarily involves microbiological hazards, since the majority of evident water-related health problems are the result of microbial contamination [2]. In recent years, bottled water gained popularity in several countries including UAE. Bottled water is a beverage that is rapidly gaining in popularity and according to the latest World's Water report the average annual consumption is over 100 liters per person in 15 countries from the world ranking, and over 200 liters per person in the countries at the top of this ranking, namely Mexico, Italy, and the United Arab Emirates [3]. Over the years, however, concerns have been raised about the microbial quality of bottled water marketed worldwide with

Manuscript received September 30, 2014; revised December 17, 2014.

Merfat Ebrahim Al-Moosa, Munawwar Ali Khan, and Usama Alalami are with the Department of Natural Science \& Public Health, Zayed University, Dubai, UAE (e-mail: U2705864@zu.ac.ae, Munawwar.Khan@zu.ac.ae, Usama.Alalami@zu.ac.ae).

Arif Hussain is with School of Life Sciences, Manipal University, Dubai, P. O. Box: 345050, UAE (e-mail: arifhussain@manipaldubai.com). several studies have documented the detection of coliform and heterotrophic bacteria in bottled water [4]-[6].

In the UAE, bottled drinking water is supplied by several water companies and most of them use techniques such as ozone disinfection, membrane filtration, UV disinfection to reach the maximum standard of water safety before refilling the bottles and distributing to the consumers. The common mode of bottled drinking water distribution in public places is through water dispenser machines and most of these water dispensers, in particular their location at schools and university campuses are prone to contamination by microorganisms, especially if these water dispenser machines are not maintained on a regular basis.

Several previous studies showed that vending machines can contain bacteria that are harmful to human and cause others infections and diseases to spread [7]-[10]. In addition, drinking water is also the route of dissemination of antibiotic-resistant organisms among human and animal populations, including spread of the resistance genes in the natural bacterial ecosystems [11], [12]. If the sources of contamination are known, the problem will decrease as concerned health authorities can work to solve the problem by spreading awareness among people regarding using simple and effective methods of cleaning the machine regularly to keep the water quality safe. In the UAE, the concerned municipalities of each emirate routinely monitor the bottled drinking water to safeguard public health by limiting possible microbial contamination of water. Although several studies assessed the microbial quality of bottled mineral waters in various countries [7]-[10], however, there hasn't been any specific study in the UAE on the evaluation of microbiological quality, particularly at the point of the end user of drinking water from water dispenser machines. The aim of this study was to investigate the microbial quality of drinking water distributed through water dispenser machines located in different schools and university campuses in the emirate of Ajman, UAE.

\section{MATERIALS AND METHODS}

In order to evaluate the microbial quality of drinking water distributed in the schools and universities in the emirate of Ajman, 3 universities and 19 schools were selected. Ajman municipality was part of the supervision and provided a prior training program to the first author. The samples were collected from schools and universities after receiving an official approval from the administration. A few questions regarding sanitation and maintenance of the machine were asked on the spot and noted down. The water samples were collected directly from the water dispenser machine within the school and university premises in a pre-sterilized $500 \mathrm{ml}$ 
bottle and upon collection, drinking water samples were taken to the microbiological laboratory and analyzed same day or stored at refrigeration temperature in the original bottle until tested. The colilert reagent was used to identify the presence of total coliform and E.coli, and Pseudomonas agar was used to detect $P$. aeruginosa using membrane filtration method.

The colilert reagent test was used to identify total coliform and E.coli present in the drinking water samples. Briefly, 100 $\mathrm{ml}$ of sample from the $500 \mathrm{ml}$ bottle of each collected sample was taken by pouring it into a $100 \mathrm{ml}$ size bottle. The colilert reagent was added and the vessel was sealed properly and mixed till the powder was dissolved, and the samples were incubated for 24 hours at $35^{\circ} \mathrm{C}$. The presence of total coliform group bacteria confirmed by changes in water sample color to yellow, which confirmed the presence of total coliform group members. In order to confirm the presence of E.coli, the total coliform positive samples were exposed to the UV device to observe the blue color fluorescence emitted by E. coli.

\section{RESULTS AND DISCUSSION}

A total of 49 drinking water samples collected and analyzed for Pseudomonas aeruginosa, E.coli and total coliform. The overall results showed that 25 out of 49 samples $(51 \%)$ were unsatisfactory (Table I).

\begin{tabular}{ccc}
$\begin{array}{c}\text { TABLE I: BACTERIOLOGICAL ANALYSIS OF DRINKING WATER FROM } \\
\text { WATER DISPENSER MACHINES }\end{array}$ \\
\hline Indicator bacteria & $\begin{array}{c}\text { Number of water } \\
\text { samples tested } \\
(n=49)\end{array}$ & $\begin{array}{c}\text { Water quality category (as } \\
\text { per GSO guideline) }\end{array}$ \\
\hline $\begin{array}{c}\text { Absence of bacterial } \\
\text { indicators }\end{array}$ & 24 & Satisfactory \\
$\begin{array}{c}\text { Total coliform only } \\
P . \text { aeruginosa } \text { only }\end{array}$ & 6 & Unsatisfactory \\
$\begin{array}{c}\text { Total coliform and } P . \\
\text { aeruginosa }\end{array}$ & 19 & Unsatisfactory \\
Fecal coliform & 10 & Unsatisfactory \\
E.coli & 0 & - \\
\hline
\end{tabular}

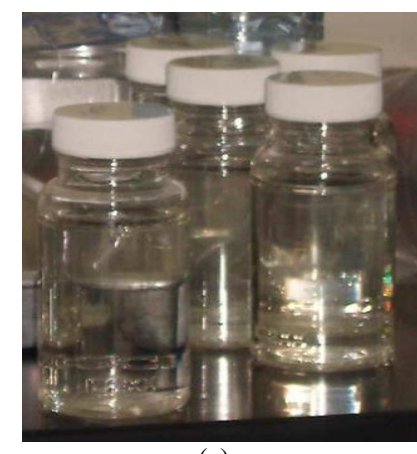

(a)

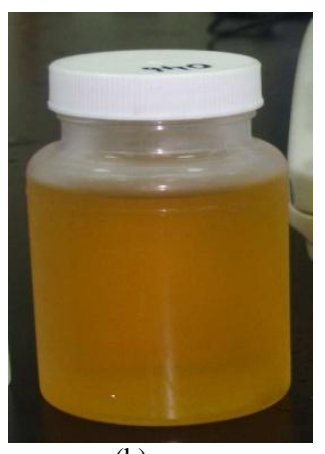

(b)
Fig. 1. (a) Water sample directly after adding the colilert reagent and before incubation (b) Water sample after 24 hours of incubation at a temperature of $35^{\circ} \mathrm{C}$.

Some of these unsatisfactory drinking water samples either detected total coliform group members (6/49), or $P$. aeruginosa (19/49) and some samples had both (10/49). The results showed that out of 49 samples, 16 were found contaminated by total coliform group members only. Since the presence of total coliform group members indicates the possibility of the occurrence of E.coli, the samples were further analyzed by using a UV device to know the presence or absence of E.coli. All of the 16 samples were found negative for the presence of $E$. coli. According to the UAE standards, drinking water should not contain any microbial cell present in water [13]. Fig. 1 shows the colilert test result for the water samples before and after conducting the test.

The results have shown that out of 49 samples, 19 samples were contaminated with $P$. aeruginosa only, whereas 10 out of 25 unsatisfactory samples were found to be contaminated with both total coliform and $P$. aeruginosa (Table I). The number of colonies of $P$. aeruginosa ranged between 4 to 200 per $250 \mathrm{ml}$ of the sample using the most probable number (MPN) method (Fig. 2 and 3).

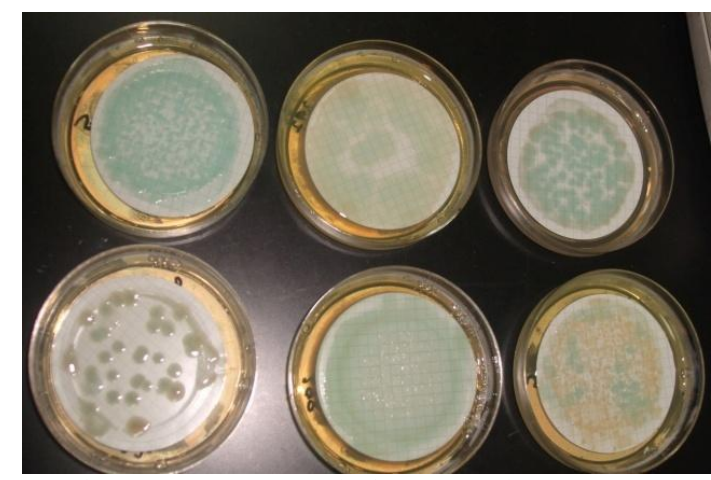

Fig. 2. P. aeruginosa colonies on Pseudomonas agar.

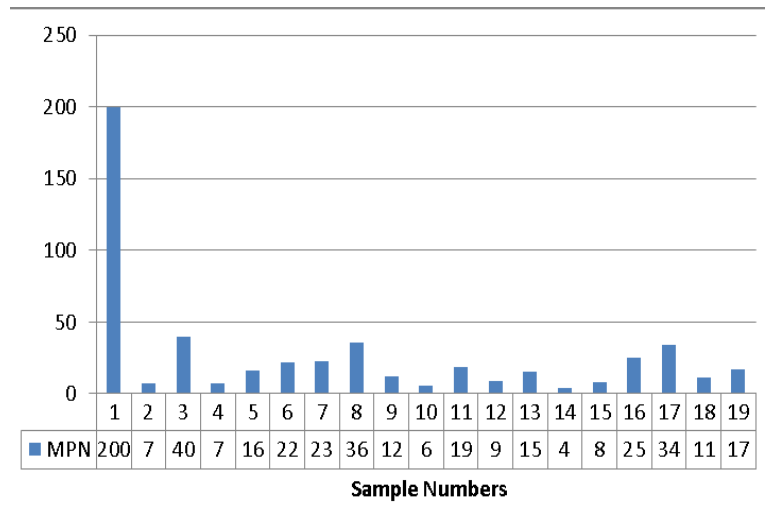

Fig. 3. P.aeruginosa colonies count (per $250 \mathrm{ml}$ ) in Pseudomonas positive drinking water sample by MPN method.

This study is the first of its kind in the UAE to evaluate the microbiological quality of drinking water from water dispenser machines in the several schools and universities located in the emirate of Ajman. The quality of drinking water before providing approval to the concerned water company was found satisfactory for all chemical indicators. However, during the sampling period, out of 49 samples 4 were found unsatisfactory as the TDS (total dissolved solids) range was observed between $74 \mathrm{mg} / \mathrm{L}$ to $100 \mathrm{mg} / \mathrm{L}$. According to Ajman municipality, as per UAE standards, the TDS of drinking water should range between 100-600 mg/L. According to WHO, the minimum TDS in the drinking water should be $100 \mathrm{mg} / \mathrm{L}$ [14]. The drinking water samples with less than $100 \mathrm{mg} / \mathrm{L}$ have been reported to affect children by slowing physical development and increasing the number of abnormalities, whereas in adults, it can cause hypertension, ischemic heart disease and ulcers [14], [15]. In this study, 4 samples with low TDS have also shown the presence of $P$. aeruginosa. These samples were from an unsatisfactory brand with $P$. aeruginosa colonies count of less than 200 . It 
means that the bacterial growth, increased during the storage and distribution phase with a possibility of health risk to the consumers either from low TDS or presence of $P$. aeruginosa.

In this study, out of 35 samples collected from the water dispenser machine in schools, 24 (69\%) were found unsatisfactory due the occurrence of coliform bacteria and $P$. aeruginosa or both. However, out of 11 samples from the three university campuses, only one was found unsatisfactory. All the unsatisfactory water samples were collected from water dispenser machines, which were stated to be cleaned regularly and maintained by the school administration. There are several factors that might lead to the occurrence of microbial growth; these can be identified from the location and the overall appearance of the water dispenser machines. It is likely that water contamination might result from the surroundings or way of handling or prevailing environmental conditions, or if the machine are located near the toilet, or outside the school which might lead sand and other small particles to enter the water reservoir. Furthermore, there are other factors such as, cleaning of the water dispenser machines from the outside or the machine might be old and not maintained for a long time. Under these conditions, the chances of the occurrence of bacteria might increase, but most probably, these factors have not affected the overall results, because in this study, about half of the drinking water samples were taken from machines for which the general appearance was not satisfactory but the result were found negative for presence of bacteria. Therefore, the most important factor which should be taken into consideration is the hygienic conditions of the water dispenser machine from inside. Another possibility is that in the water was contaminated with at least one bacterium before it was supplied to the customer. It was also found that all the water brands were tested for chemical and microbiological indicators before approval was given to the water company distributors. Only one of the water brands was found to be contaminated with $P$. aeruginosa, however, this particular water brand was available in one of the schools participated in the study and the sample was found contaminated with $P$. aeruginosa only, which clearly indicates that the water was contaminated before distribution with the low number of $P$. aeruginosa cells and this bacterium multiplied during its distribution via dispenser machine Moreover, the number of colonies of $P$. aeruginosa were found to be high in the range of $4-51$ per $250 \mathrm{ml}$ of water sample.

In total, only 49 samples were collected from the schools/universities that seem to be very less to fully elucidate the overall microbiological quality of drinking water from water dispensers across the whole emirate. It was due to the sample collection timing, which was probably not suitable for some schools since most of the schools were closed due to examination period which didn't help in covering many schools in the area. Moreover, the feedback regarding machine maintenance didn't indicate that if there was a regular cleaning or check up from the water provider as stated by the school administration. This clearly illustrates that more clarifications should be sought from the water distribution company responsible for cleaning the machines. This information can be obtained from the school or the drinking water distributors providing water to the client or even contact companies which are specialized in cleaning these machines to minimize the public health risk of drinking contaminated water.

The unsatisfactory water samples found to have variable microbial quality results as some of the water samples were found positive only for the total coliform group members, whereas some only for $P$. aeruginosa and other samples were positive for both of these bacteria. In total, 16 out of 49 samples which are $32 \%$ of the overall results detected total coliform. A quite similar study detected coliform bacteria in $20 \%$ of the drinking water samples from vending machines [5]. The microbial contamination can be mainly from soil/dust or due to the presence of some insects, but most of the bacteria belonging to the total coliform group do not cause serious health effects since they are considered harmless [8], [9]. However, this does not mean to neglect the problem of occurrence of the total coliform group bacteria. The detection of total coliform can help in further investigation for the presence of fecal coliform, specifically the presence of $E$. coli can lead to several health effects in children, elderly, and immunocompromised people [15]. However, in this study none of the drinking water samples detected E.coli.

On the other hand, $39 \%$ of samples showed the presence of $P$. aeruginosa. This bacterium has been detected in bottled water samples by several other studies [6]-[10]. The presence of this bacterium mainly indicates low nutrient environment, as it lives in soils, water, and hot or moisture environment [6]-[8]. It causes many side effects, especially to the immuno-compromised people who are already weak and responsible for the common outbreaks and infections such as respiratory system infections, urinary tract infections, and various types of systematic infections [5].

This study only investigated bacteria, such as $P$. aeruginosa, total coliform and E.coli. However, several previous studies included some other types of bacteria, such Salmonella spp., Shigella, Vibrio cholera and Campylobacter [4], [16], [17]. These species are considered to be very important since these pose high health risks and might occur in drinking water as well [1]. The presence of total coliform doesn't always indicate the presence of fecal coliform as there are other types of pathogenic microorganisms which might be found [2]. Therefore, presence and absence of other harmful bacteria should also be included in the overall evaluation of drinking water microbiological quality. Temperature is considered as one of the significant factors that might lead to the growth of total coliform. Most of the water dispenser machines in the schools and universities were kept at a room temperature. However, a study showed that total coliform in water increases when the temperature is higher than $15^{\circ} \mathrm{C}[18]$. For a country like UAE, where a high temperature is common during most of the year, the possibility of occurrence of total coliform is very high, especially when these water dispenser machines are located in the playing area of the school or being exposed directly to sun heat. At least ten water dispenser machines located in such areas were found positive for $P$. aeruginosa and total coliform bacteria. It is likely that the temperature was a significant factor for the regrowth of bacteria in these water dispenser machines. 


\section{CONCLUSION}

In conclusion, out of total 49 drinking water samples taken from water dispenser machines, 25 samples (51\%) were found positive with either total coliform members or $P$. aeruginosa. In particular, drinking water samples positive (39\%) with $P$. aeruginosa is a cause of major concern as this particular bacterium is considered as an opportunistic pathogen and its occurrence in the drinking water distributed via water dispenser machines located in schools can pose a serious health risk to the children. Therefore, maintenance of proper hygienic conditions of water dispenser machines is very important for the health and safety of the consumer. Therefore, the concerned authorities should implement stricter regulations to ensure safe drinking water quality in the schools and universities located in Ajman. Furthermore, more awareness is needed about maintaining the microbial quality of drinking water distributed via water dispensers in the public schools and universities operating within the UAE.

\section{ACKNOWLEDGMENT}

The authors would like to thank Food, Environment and Microbiology laboratory staff in the Public health and Environment department of the Ajman municipality for providing the necessary guidance and training relevant to this study. Their cooperation and arrangement for the collection of drinking water samples from the public schools and universities is highly appreciated. We are thankful to schools and university administration for agreeing to take part in this study.

\section{REFERENCES}

[1] H. Alhassan and P. A. Kwakwa, "When water is scarce: the perception of water quality and effects on the vulnerable," Journal of Water, Sanitation and Hygiene for Development, vol. 4, pp. 43-50, January 2014.

[2] A. Farkas, M. Drăgan-Bularda, D. Ciatarâş, B. Bocoş, and S. Țigan, "Opportunistic pathogens and faecal indicators in drinking water associated biofilms in Cluj, Romania," J. Water Health, vol. 10, pp. 471-483, July 2012.

[3] M. Diduch, Z. Polkowska, and J. Namieśnik, "Factors affecting the quality of bottled water," J. Expo. Sci. Environ. Epidemiol., vol. 23, pp 111-119, October 2013.

[4] J. Bharath, M. Mosodeen, S. Motilal, S. Sandy, S. Sharma, T. Tessaro, K. Thomas, M. Umamaheswaran, D. Simeon, and A. A. Adesiyun, "Microbial quality of domestic and imported brands of bottled water in Trinidad," Int. J. Food Microbiol., vol. 81, pp. 53-62, April 2003.

[5] C. Chaidez, P. Rusin, J. Naranjo, and C. P. Gerba, "Microbiological quality of water vending machines," International Journal of Environmental Health Research, vol. 9, pp. 197-206, July 1999.

[6] G. Liguori, I. Cavallotti, A. Arnese, C. Amiranda, D. Anas-tasi, and I. F. Angelillo, "Microbiological quality of drinking water from dispensers in Italy," BMC Microbiology, vol. 10, pp. 1-5, January 2010.

[7] M. E. Zamberlan da Silva, R. G. Santana, M. Guilhermetti, I. Camargo Filho, E. H. Endoc,T. Ueda-Nakamura, C. Vataru Nakamura, and B. P. Dias Filho, "Comparison of the bacteriological quality of tap water and bottled mineral water," International Journal of Hygiene and Environmental Health, vol. 211, pp. 504-509, September 2008.

[8] L. Varga, "Bacteriological quality of bottled natural mineral waters commercialized in Hungary," Food Control, vol. 22, pp. 591-595, October 2011.

[9] M. Vital, D. Stucki, T. Egli, and F. Hammes, "Evaluating the growth potential of pathogenic bacteria in water," Applied and Environmental Microbiology, vol. 76, pp. 6477-6484, August 2010.

[10] J. Schillinger and S. D. Vall Knorr, "Drinking water quality and issues associated with water vending machines in the city of Los Angeles," Journal of Environmental Health, vol. 66, pp. 25-31, January 2004.
[11] F. Baquero, J. L. Martinez, and R. Canton, "Antibiotics and antibiotic resistance in water environments," Current opinion in Biotechnology, vol. 19, pp. 260-265, June 2008.

[12] M. F. Falcone-Dias, I. Vaz-Moreira, and C. M. Manaia, "Bottled mineral water as a potential source of antibiotic resistant bacteria," Water. Res., vol. 46, pp. 3612-3622, July 2012.

[13] United Arab Emirates. (2012). Gulf Cooperation Council Standarisation organization (GSO) Draft of Technical Regulation for unbottled drinking water. [Online]. pp. 1-12. Available: http://www.puntofocal.gov.ar/notific_otros_miembros/are205_t.pdf

[14] F. Kozisek. (2005). Health risks from drinking demineralised water. World Health Organization Report. [Online]. pp. 148-163. Available: http://www.who.int/water_sanitation_health/dwq/nutrientschap12.pdf

[15] W. Clark, J. F. Sontrop, J. M. Macnab, M. Salvadori, L. Moist, R. Suri, and A. X. Garg, "Long term risk for hypertension, renal impairment, and cardiovascular disease after gastroenteritis from drinking water contaminated with Escherichia coli O157: H7: a prospective cohort study," BMJ, vol. 341, pp. 1-9, November 2010.

[16] M. Figueras and J. Borrego, "New perspectives in monitoring drinking water microbial quality," International Journal of Environmental Research and Public Health, vol. 7, pp. 4179-4202, December 2010.

[17] K. J. Lamka, M. W. Le Chevallier, and R. J. Seidler, "Bacterial contamination of drinking water supplies in a modern rural neighborhood," Applied and Environmental Microbiology, vol. 39 , pp. 734-738, April 1980.

[18] M. LeChevallier, "Conditions favouring coliform and HPC bacteria growth in drinking-water and on water contact surfaces," in Heterotrophic Plate Counts and Drinking-Water Safety, J. Bartram, J. Cotruvo, M. Exner, C. Fricker, A. Glasmacher, Eds. IWA Publishing, London, 2003, pp. 178-180.

Merfat Ebrahim Al-Moosa was a student with a bachelor of science degree in environmental health major at the Department of Natural Science \& Public Health, Zayed University, Dubai, UAE.

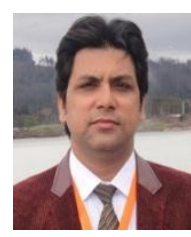

Munawwar Ali Khan is an associate professor and coordinator of environmental science and sustainability cluster in the Department of Natural Science and Public Health, College of Sustainability Sciences \& Humanities at Zayed University, Dubai, United Arab Emirates. He received his $\mathrm{Ph} . \mathrm{D}$. degree in 2001 in the area of environmental engineering from the Department of Urban Engineering at the University of Tokyo, Japan. His research work is in the general area of environmental microbiology and biotechnology. His specific focus is on developing and applying in situ (direct) molecular biological methods to detect microbial contaminants in water, wastewater, reclaimed, recreational water, food and clinical samples.

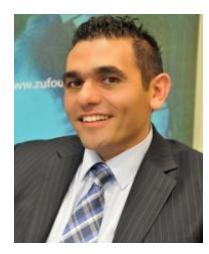

Usama ALalami is an assistant dean of the College of Sustainability Sciences and Humanities, and an associate professor in health sciences, at the Department of Natural Sciences and Public Health (NSPH) at Zayed University. Prior to joining Zayed University, he was the programme director of the B.Sc. Health Studies degree and senior lecturer in Human Anatomy and Physiology at Birmingham City University, UK. Prior to joining Birmingham City University, he worked as a postdoctoral research associate at the Wellcome Trust Biocentre, University of Dundee on projects involving therapeutic cloning. He holds a $\mathrm{PhD}$ degree in breast cancer and leukemia from the University of Wolverhampton.

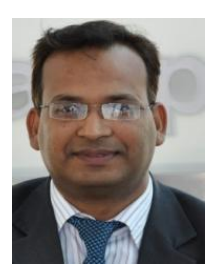

Arif Hussain is an assistant professor in the School of Life Sciences at Manipal University, Dubai, United Arab Emirates. Dr. Hussain has received his master of science degree in biotechnology and doctor of philosophy degree in molecular oncology/bio sciences. $\mathrm{He}$ is the member of various scientific associations and editorial board. He has presented his findings in several scientific conferences across the nation and published in reputed peer-reviewed scientific journals. He has contributed DNA sequences in the universal nucleotide repository database genbank. Dr. Hussain's current research interests include understanding the underlying molecular events in cancer progression and their therapeutic interventions and applied biotechnology. 